\title{
UMA AUTOETNOGRAFIA DA FORMAÇÃO PARA ASSISTÊNCIA JURÍDICA ÀS MULHERES EM SITUAÇÃO DE VIOLÊNCIA NA UFPA
}

\author{
Luanna Tomaz de Souza ${ }^{1}$
}

Resumo: O presente artigo realiza uma autoetnografia na perspectiva de investigar os desafios para a formação de profissionais para a assistência jurídica de mulheres em situação de violência. Parte-se também de uma metodologia feminista, além da utilização da autoetnografia, da pesquisa bibliográfica e documental. São revelados avanços no sentido de oferecer mais oportunidades para estudantes lidarem com a defesa dos direitos das mulheres. Todavia, ainda há desafios de difícil superação que envolvem os limites do próprio ensino jurídico, do Direito e do atendimento e que precisam ser evidenciados e enfrentados como a estrutura oferecida e a formação intersubjetiva.

Palavras-chave: Autoetnografia; Violência contra a mulher; Violência doméstica; Assistência jurídica; Ensino jurídico.

\section{A SELF-ETHNOGRAPHY OF TRAINING FOR LEGAL ASSISTANCE FOR WOMEN IN SITUATION OF VIOLENCE AT UFPA}

\begin{abstract}
This article performs an autoethnography from the perspective of investigating the challenges for training professionals to provide legal assistance to women in situations of violence. It also starts from a feminist methodology, in addition to the use of autoethnography, bibliographical and documentary research. Progress is revealed in terms of offering more opportunities for students to deal with the defense of women's rights. However, there are still challenges that are difficult to overcome that involve the limits of legal education, Law and care and that need to be highlighted and faced as the structure offered and intersubjective training.
\end{abstract}

Keywords: Autoethnography; Violence against women; Domestic violence; Legal assistance; Legal education.

\section{Introdução}

No Brasil, tem crescido significativamente as políticas voltadas ao enfrentamento às violências cometidas contra as mulheres, em especial com o advento da Lei Maria da Penha, a Lei $11.340 / 06^{2}$. Uma das políticas que ganha relevo com a lei é a assistência judiciária, assim designada no texto legal:

\footnotetext{
${ }^{1}$ Pós doutora em Direito (PUC-RIO), Doutora em Direito (Universidade de Coimbra), Coordenadora da Clínica de Atenção à Violência, Coordenadora do Grupo de Estudos e Pesquisas Direito Penal e Democracia, Professora da Faculdade de Direito, do Programa de Pós-Graduação em Direito e do Programa de Pós-Graduação em Direito e Desenvolvimento da Amazônia da UFPA. E-mail: luannatomaz@ufpa.br. ORCID: https://orcid.org/0000-0002-8385-8859.

${ }^{2}$ Cria mecanismos para coibir a violência doméstica e familiar contra a mulher, nos termos do $\S 8^{\circ}$ do art. 226 da Constituição Federal, da Convenção sobre a Eliminação de Todas as Formas de Discriminação contra as Mulheres e da Convenção Interamericana para Prevenir, Punir e Erradicar a Violência contra a Mulher; dispõe
}

Revista de Pesquisa e Educação Jurídica | e-ISSN: 2525-9636 | Encontro Virtual | v. 7 | n. 2 | p. 01 - 20 | Jul/Dez. 2021. 


\section{CAPÍTULO IV - DA ASSISTÊNCIA JUDICIÁRIA}

Art. 27. Em todos os atos processuais, cíveis e criminais, a mulher em situação de violência doméstica e familiar deverá estar acompanhada de advogado, ressalvado o previsto no art. 19 desta Lei.

Art. 28. É garantido a toda mulher em situação de violência doméstica e familiar o acesso aos serviços de Defensoria Pública ou de Assistência Judiciária Gratuita, nos termos da lei, em sede policial e judicial, mediante atendimento específico e humanizado.

Alcança visibilidade com a Lei o debate acerca da assistência jurídica especializada às mulheres em situação de violência, sendo reconhecida a importância desse serviço como forma de garantir que este processo não seja repleto de percalços que dificultem à mulher em situação de violência o acesso à justiça. Isso tem aumentado o número de serviços oferecidos. Para Ana Flauzina (2015), não podemos ignorar a centralidade da assistência judiciária qualificada para compreensão das dinâmicas processuais e das opções efetivas ofertadas às vítimas.

É relevante, contudo, refletir acerca dos limites e potencialidades desse tipo de serviço, em especial analisando a formação de profissionais, área que não tem sido foco de muitos estudos. Desta forma, este artigo realiza uma autoetnografia na perspectiva de investigar os desafios para a formação de profissionais para a assistência jurídica de mulheres em situação de violência.

Incorpora-se, nesse estudo, uma experiência de cerca de quinze anos de professora universitária de prática jurídica, que ao longo do tempo desenvolveu diversos projetos de atendimento às mulheres em situação de violência na universidade.

A epistemologia feminista tem nos ensinado porque, nós mulheres, precisamos contar a nossa história e como relatos da trajetória de sujeitos subalternizados são uma importante fonte para explicar como se estruturam as diversas relações sociais. Isso permite que possamos ir além dos "grandes feitos" trazidos pela história oficial protagonizados por homens que se constituem em espelhos que modulam comportamentos e a conquista dos espaços públicos (SOUZA, F. 2019).

Desta feita, escolheu-se a autoetnografia a partir da delimitação do foco do estudo na compreensão da descrição, da convivência, dos sentimentos e da aprendizagem do sujeito que

sobre a criação dos Juizados de Violência Doméstica e Familiar contra a Mulher; altera o Código de Processo Penal, o Código Penal e a Lei de Execução Penal; e dá outras providências. 
investiga a si mesmo em sua pesquisa (BOSSLE E ROCHA, 2011). Selma Bezerra (2009) define autoetnografia como uma pesquisa cujo objetivo é narrar experiências pessoais para criticar e investigar práticas sociais que envolvem a vida pessoal ou os ambientes profissionais de um pesquisador ou pesquisadora.

Esta questão nos ajuda a refletir sobre o que inspira uma professora a pesquisar sua própria vivência. De acordo com Donna Haraway (1995), as teorias feministas têm se debruçado sobre a noção de objetividade. Desenvolve-se, em contraponto, uma perspectiva da epistemologia como um saber localizado. Trata-se de um olhar que parte de um corpo humano, localizado territorial, social e temporalmente, e, por isso, produz-se um conhecimento corporificado, localizado e parcial. Demanda, para tanto, posicionar-se, ou seja, verificar como o conhecimento é produzido a partir de um local social e político.

Esta pesquisa assume assim uma perspectiva de conhecimento situado. A presente autorreflexão contribui para analisar os limites da formação para a assistência judiciária às mulheres em situação de violência. Essa representação de demandas e de dinâmica do ambiente acadêmico, todavia, pode importar também em observar problemas que também ocorrem na assistência como um todo.

Parte-se também de uma metodologia feminista de análise pautada na perspectiva de transformação da realidade para a defesa e promoção dos direitos das mulheres (SOUZA, SILVA E YOSANO, 2019).

Desenvolve-se, como subsídio, uma pesquisa bibliográfica e documental em textos sobre temas como a assistência jurídica, a violência doméstica, a autoetnografia e os direitos das mulheres, privilegiando aqueles que tracem suas análises a partir do referencial feminista. Além do relato de experiência, percorro os textos produzidos por mim, ao longo do tempo, para autoavaliar as preocupações historicamente desenvolvidas.

\section{Desenhando minha cena}

Nasci no Macapá-Amapá e cresci em Belém-Pará. Duas cidades do norte do país com graves problemas de acesso a políticas públicas. Além disso, cresci com relatos de mulheres que sofreram violência doméstica como minha avó e minha mãe. Isso fez com que desde nova me interessasse pelo tema do feminismo. Na graduação, em Belém, me aproximei dos movimentos feministas, em especial com o trabalho desenvolvido pelo Fórum de 
Mulheres da Amazônia Paraense ${ }^{3}$ e pela Marcha Mundial de Mulheres ${ }^{4}$. Sem sombra de dúvidas as vivências do sujeito marcam sua trajetória e repercutem na forma com que atua sobre o mundo.

Enquanto estudante feminista, atuante no Núcleo de Prática Jurídica, recordo-me de atender mulheres em situação de violência e ouvir de professores que nada era possível de ser feito para resolver os problemas que eram postos. Isso inclusive motivou minha dissertação (SOUZA, L. 2009). A violência doméstica e familiar cometida contra as mulheres também passou a ser tema dos meus estudos doutorais (SOUZA, L. 2016) e de outras pesquisas autônomas (SOUZA, L. 2018; SOUZA, L. 2019).

Como advogada, passei a atuar junto a organizações da sociedade civil $^{5}$ e a assistir mulheres em situação de violência. Como professora, comecei ministrando aulas em instituições privadas, desde 2007. Em uma dessas instituições desenvolvi minha primeira iniciativa de atendimento às mulheres em situação de violência. Eu realizava atendimento, nos meus horários de aula, no Núcleo de Prática Jurídica (NPJ), para mulheres em situação de violência. Eu divulgava pessoalmente na rede de atendimento a atividade e capacitava, nos horários de aula, os/as discentes.

Em 2009, ingresso na Universidade Federal do Pará como professora de prática penal. No ano de 2010, implantei um projeto de extensão para assistência jurídica a mulheres em situação de violência no NPJ. O projeto consistia em reservar um dia específico para atendimento (sextas-feiras) no espaço do NPJ. Ao longo do tempo, fui aperfeiçoando as mecânicas de atendimento com material próprio, discussão interna dos casos, capacitações, atividades externas e monitoramento das demandas.

Em 2013, esse projeto foi ampliado em uma perspectiva de programa de ensino a partir de novos editais de fomento apresentados pelo governo federal. Isso contribuiu para

\footnotetext{
${ }^{3}$ Movimento de articulação que reúne vários movimentos feministas e de mulheres da Amazônia. Criado em 1996, um ano após a Conferência de Beijing - IV Conferência Mundial sobre a Mulher (1995). O Fórum foi criado a partir do movimento "Articulação de Mulheres pró-Beijing Pará".

${ }^{4}$ A Marcha foi inspirada a partir de uma manifestação realizada em 1995, em Quebec, no Canadá. Em 2000 foi feita a primeira ação internacional que mobilizou milhares de grupos de mulheres em mais de 150 países e territórios. MMM. Nossa história. Disponível em: https://www.marchamundialdasmulheres.org.br/amarcha/nossa-historia/. Acesso em: 05 abr. 2020.

${ }_{5}^{5}$ Integrei inicialmente a comissão estadual de mulheres advogadas da Ordem dos Advogados do Brasil -Seção Pará (OAB-PA) e depois presidi a comissão da criança do adolescente e de direitos humanos da OAB-PA, sucessivamente.
} 
aumentar o número de discentes envolvidos/as e aperfeiçoar as formas de capacitação aglutinando técnicas e professoras do próprio Núcleo.

No ano de 2016, resolvi transformar o projeto criando a Clínica de Atenção à Violência (CAV). A Clínica conta com a participação de docentes de diferentes áreas envolvendo profissionais, docentes e discentes de Direito, do Serviço Social, da Enfermagem e da Psicologia.

A Clínica de Atenção à Violência realiza, nas sextas-feiras, atendimento a pessoas em situação de violência. A partir dos casos, os/as discentes refletem, em conjunto, sobre as possíveis formas de resolução. A partir de grupos de trabalho também constroem possibilidades de intervenção mais coletivas sobre o problema, em uma perspectiva de litigância estratégica, como a proposição de políticas públicas. Segundo o Fundo Brasil de Direitos Humanos (2016, p.8):

\footnotetext{
Litigância é um termo usado no Direito e quer dizer o ato de mover ações na Justiça e de atuar perante o Judiciário. Litigância estratégica é uma ampliação desse conceito para abranger não só a noção tradicional do Direito, mas também um conjunto de ações de advocacy e comunicação para incidência no Legislativo e no Executivo, com o objetivo de viabilizar políticas públicas que defendam e efetivem direitos dos diversos segmentos vulneráveis da sociedade. Ela é estratégica porque não é qualquer ação, mas sim aquela que tem uma dimensão emblemática, capaz de criar precedentes e gerar resultados positivos. Tais resultados terão efeito multiplicador, transformando-se em exemplos bem-sucedidos a serem aplicados em outros casos similares, possibilitando assim um salto na garantia dos direitos humanos
}

Passado mais de dez anos desta trajetória é importante percorrer esses caminhos e repensar as formas de atendimento desenvolvidas. Após analisar diversas políticas públicas desenvolvidas, é importante também refletir sobre meus próprios caminhos e percalços na assistência jurídica às mulheres como forma de contribuir nesse processo dinâmico de formação e atendimento para a população.

\section{Por entre modelos: do NPJ à Clínica na assistência às mulheres}


Durante toda minha docência estive envolvida na prática jurídica. Em 2016, cheguei a assumir, inclusive, a coordenação do NPJ-UFPA. Como professora do núcleo, durante esses anos, percebi muitos limites do modelo e me deparei com algumas críticas desenvolvidas.

Segundo Bello e Ferreira (2018), os processos judiciais geralmente envolvem casos repetitivos, contencioso de massa, com complexidade jurídica baixa, envolvendo questões patrimoniais ou de família. O/a discente acaba recebendo passivamente instruções sobre as soluções, elaborando peças processuais a partir de modelos e acompanhando parcialmente a tramitação dos processos.

Esse modelo de escritório, com grande demanda, mas com pouca variedade faz com que os alunos e alunas se concentrem mais na produção das peças e pouco no atendimento em si. Ademais, a rotatividade de estudantes a cada semestre faz com que, muitas vezes, não haja continuidade nos atendimentos.

Decorre disso uma formação prática com inúmeras deficiências, em especial para o atendimento de pessoas em situação de violência, tais como: a) dificuldade de escuta; b) falta de compromisso; c) cultura litigante pautada no judiciário; d) pouco espaço para a reflexão e construção de soluções com a assistida; e) baixa empatia; f) distância do que aprende em sala de aula; g) pouco espaço para a reflexão e construção de soluções com a assistida; h) reafirmação de uma visão tradicional de vítima; i) reprodução de um modelo de saber competente com necessidade de impor julgamentos.

Há muito tempo esse tipo de experiência docente tem me incomodado. Em minha dissertação, analisando ainda minha experiência atendendo mulheres em situação de violência como professora de Núcleos de Práticas Jurídicas em instituições privadas, destaquei:

Estas(es) alunas(os) são treinadas(os) em seu curso para, ao ouvir um determinado relato, identificar os pontos relevantes, juridicamente, e apontar as soluções, esperando que os atendimentos sejam de curta duração e extremamente objetivos. Contudo, naquele momento, a mulher deseja contar toda sua trajetória e espera ali ser ouvida. Entretanto, constantemente eu me deparava com a agonia de alguns alunos e alunas sem paciência para aquele tipo de escuta (..) (SOUZA, L. 2009, P. 158)

Quando iniciei um projeto de assistência jurídica a mulheres em situação de violência me deparei com desafios também relacionados com modelo de ensino privado em que você se vê mais pressionada a demanda de mercado com falta de bolsas para projetos, número grande de turmas e discentes, falta de interesse institucional nesse tipo de ação. 
Segundo Boaventura de Souza Santos (2005), essas instituições são mais pressionadas para transformar conhecimento e os seus recursos humanos em produtos que devem ser explorados comercialmente e a transformar a própria universidade em marca.

Todavia, mesmo em uma instituição pública, chama atenção os limites do modelo do NPJ principalmente para este tipo de demanda. O NPJ, por exemplo, não se amolda a demandas urgentes. Em regra, os atendimentos são feitos uma vez por semana. Caso a cliente deseje entrar com alguma ação judicial deve, na outra semana, entregar os documentos, para que possam ser preparadas as peças processuais nas semanas seguintes. Tem-se aí, em média, três a quatro semanas o protocolo das peças, levando-se em conta a avaliação e as devidas correções da professora orientadora.

Isso sem contar que, na maioria das vezes, não há uma estrutura adequada para atendimento de casos que envolvam situações de violência. As salas não são isoladas acusticamente, não têm mesas circulares ou espaços para dinâmicas que se distinguem do modelo de atendimento advocatício tradicional, centrado na elaboração de peças. Também não há espaço adequado para as crianças, sendo que muitas mulheres vêm acompanhadas delas.

Como forma de esgarçar esse modelo e possibilitar novas formas de garantir o atendimento às mulheres, uma demanda sempre frequente dos NPJs, passei a criar projetos variados. Iniciei como um projeto de extensão e depois como projeto de ensino. O modelo de ensino por projetos é interessante, mas um de seus principais desafios é a vinculação a editais que dependem de políticas governamentais.

Em especial no Governo Lula, houve um grande investimento na expansão do ensino superior com diversos editais e bolsas de pesquisa e extensão. A extensão universitária sempre foi preterida no ensino superior e essas ações contribuíram para o fortalecimento dos projetos (PIMENTEL, 2015). Todavia, nos últimos anos, os editais têm se escasseado em um processo de menor investimento no ensino superior. Isso dificulta o empenho na elaboração de projetos com menos editais e bolsas disponíveis. A Capes (Coordenação de Aperfeiçoamento de Pessoal de Nível Superior), um dos maiores órgãos de financiamento à pesquisa, cortou 11.800 bolsas somente em $2019^{6}$.

\footnotetext{
${ }^{6}$ GUIA DO ESTUDANTE. Brasil tem uma das piores taxas de Ensino Superior do mundo, diz OCDE. Disponível em: https://guiadoestudante.abril.com.br/atualidades/brasil-tem-um-das-piores-taxas-de-ensinosuperior-do-mundo-diz-ocde/ . Acesso em: 16 out. 2020.
}

Revista de Pesquisa e Educação Jurídica | e-ISSN: 2525-9636 | Encontro Virtual | v. 7 | n. 2 | p. $01-20$ | Jul/Dez. 2021. 
Com o fim dos editais e com expectativa de alcançar novos resultados e uma estrutura mais autônoma busquei um novo modelo: o de clínicas jurídicas. Estas surgiram tanto na América do Norte quanto na América Latina, a partir do século XXI, com o primordial objetivo de mudar a metodologia tradicional do ensino jurídico e formar profissionais do Direito mais comprometidos com a justiça social. Diferentes formatos de clínicas jurídicas surgiram, no Brasil (LAPA, 2014).

Conforme Hurwitz (2006), para os/as estudantes de Direito, participar de clínicas de direitos humanos (uma vertente em crescimento), durante a graduação, pode trazer inúmeros benefícios. Podem se aproximar de uma prática mais pautada na mudança social, além de adquirir outras habilidades advocatícias, tendo em vista que a advocacia em direitos humanos tem especificidades. Essas habilidades envolvem a escrita de peças jurídicas, mas também, dentre outras: a) boa comunicação oral; b) habilidade de pensar criticamente e de desenvolver estratégias efetivas para solucionar problemas; c) trabalho em grupo; d) desenvolvimento de habilidades de pesquisa.

A Faculdade de Direito da Universidade Federal do Pará criou, em 2011, a Clínica de Direitos Humanos da Amazônia (CDHA), como pertencente ao Laboratório de Direitos Humanos do Programa de Pós-Graduação em Direitos Humanos (PPGD) da Universidade Federal do Pará. Em 2016, decidi criar a Clínica de Atenção à Violência (CAV), a partir dos projetos que estavam sendo desenvolvidos. Ambas as Clínicas integram a Rede Amazônica de Clínicas de Direitos Humanos. Os/as docentes vinculados/as às clínicas podem ministrar a disciplina Prática Jurídica na modalidade clínica $^{7}$ (SOUZA, L; TEIXEIRA; MESQUITA, 2020).

Estas ações visam promover novas iniciativas metodológica de ensino pautadas em questões como: a) impacto social; b) justiça social; c) transdisciplinaridade; d) diversidade metodológica; e) aliança teoria e prática; f) desenvolvimento de competências interpessoais, cognitivas e instrumentais. Todavia, ainda são muitos os desafios para que se alcancem esses resultados, principalmente ao se considerar que não há como construir ilhas diante de um problema que envolve o próprio modelo de ensino jurídico.

\section{Novos modelos e velhos problemas no desafio da formação}

\footnotetext{
${ }^{7}$ Resolução FAD/ICJ-UFPA n n 09, 06 de março de 2018.
} 
Mesmo com o desenvolvimento dessas iniciativas, os desafios têm permanecido na formação de pessoas para o atendimento de mulheres em situação de violência. É importante evidenciar os limites para que possamos perceber as possibilidades de superação. Sem isso pode-se alimentar uma lógica de precarização do atendimento que é perversa. Muitas vezes acredita-se que é necessário atender e, por isso, atende-se de qualquer jeito, sem autocrítica e monitoramento.

Em geral, o primeiro desafio no atendimento é estrutural. Para um atendimento que ofereça condições dignas é fundamental uma estrutura adequada de funcionamento, com salas individualizadas e isoladas acusticamente, material próprio, espaço para o acolhimento de crianças e atendimento grupal e uma equipe técnica de retaguarda qualificada. Isso é algo muito difícil de alcançar.

Outro desafio é o formato de aula. Continua-se criando uma lógica de atendimento uma ou duas vezes por semana ${ }^{8}$ o que atrapalha a continuidade do serviço e é muito prejudicial ao levarmos em conta que muitas demandas são urgentes e/ou exigem continuidade diária.

Outro problema que permanece é a rotatividade de discentes. Com a Clínica isso diminui, já que muitos se tornam bolsistas, mas ainda ocorre já que muitos querem viver outras experiências ao final da bolsa. Um atendimento, contudo, pode demorar meses ou anos para que chegue a uma resolução. Ademais, a troca na equipe faz com que sejam necessárias constantes capacitações.

Para além de todos esses obséquios, sem sombra de dúvidas, o maior desafio ainda é a formação subjetiva e o desenvolvimento de habilidades interpessoais. A Lei Maria da Penha afirma que a assistência jurídica deve ser específica e humanizada (art. 27), contudo, ainda é um desafio preparar profissionais do direito para esse tipo de atendimento que exige tempo de escuta, acolhida e diálogo com a pessoa envolvida, que muitas vezes está fragilizada.

Além do mais, muitas vezes a pessoa que atende deve estar preparada para lidar com saídas que vão além da judicialização. É importante que se tenha foco não apenas na causa jurídica, mas na situação da pessoa atendida e nos problemas por ela vivenciados. É exigida uma postura na qual se ouça atentamente a demanda, de forma capaz de acolher, escutar e dar respostas mais adequadas. Implica, assim, prestar um atendimento com resolutividade e

\footnotetext{
${ }^{8}$ Modelo mais tradicional em que uma equipe de estudantes atende uma vez por semana.
} 
responsabilização, orientando, quando for o caso, em relação a outros serviços e estabelecendo articulações para garantir a eficácia destes encaminhamentos (SOUZA, L, 2009).

A formação jurídica é, contudo, extremamente tecnicista, mecânica e generalista. $O$ ensino jurídico hoje é centrado na teoria e no aprendizado do conteúdo e pouco preparado para problemas mais complexos. Isso se intensificou com a proliferação dos cursos jurídicos, ampliando o processo de massificação e banalização (MENDES e REIS, 2016). Desta feita, seria fundamental apostar em uma estrutura curricular que pudesse oferecer mais subsídios para esse tipo de atendimento com mais atividades extensionistas ${ }^{9}$ e disciplinas que fossem além da lógica dogmática.

A formação das subjetividades é fundamental para o atendimento à população. É, em verdade, necessária quando desejamos uma sociedade democrática, em especial em nossa época em que autoritarismos crescem. As teorias feministas contribuíram para elucidar isto com foco em políticas de escuta e de afeto.

Autoras como bell hooks (1994) apontam a importância de laços que ajudem a mitigar o sofrimento humano por meio da empatia e da solidariedade. Isso alimenta desaprendizagens e desnaturalização de conceitos ao perceber melhor as relações de poder e os atravessamentos ideológicos e identitários que nos configuram e projetam esses sofrimentos.

Para tanto, isso envolve pensar afeto, compromisso e pertença. Vilma Piedade (2017) também nos alerta, por meio do conceito de dororidade, sobre a importância de nos aproximar mais pelas nossas dores, reconhecendo também dores historicamente invisibilizadas, no caso das mulheres negras.

Nesse contexto, Thais Borges (2017) adverte sobre a necessidade de um "sentir crítico" na atividade docente. Segundo a autora, isso exige um processo de envolvimento e autorreflexão pautado na empatia para com o outro, fruto de uma sensibilização a questões do sofrimento humano e de uma melhor percepção das relações de poder e dos atravessamentos identitários e ideológicos que nos configuram. Isso é também fundamental na assistência

\footnotetext{
${ }^{9}$ Esse aspecto é, inclusive, determinado pelas Novas Diretrizes Curriculares que "concederam importância também à extensão, a partir da menção expressiva de clínicas e projetos como atividades de extensão, sendo ainda mais ampliada com a Resolução CNE/CES no 07, de 2018, que a extensão tomou corpo de obrigatoriedade percentual nos Projetos Pedagógicos para os cursos de Direito" (SOUZA, L; TEIXEIRA; MESQUITA, 2020, p. 119).
} 
jurídicas às mulheres em situação de violência. Um devir de sensibilidade que não permita que se imponha um rol de ações, mas interações que conduzam não para a aceitação da realidade, mas para sua mudança.

Além disso, isso envolve uma dimensão de reflexão sobre a nossa própria experiência. Durante os projetos desenvolvidos muitas discentes inclusive começar a compreender processos de violência vividos. Isso era algo que não estávamos preparados para lidar: como acolher quem acolhe.

A formação de subjetividades exige uma educação que permita experiências que façam com que discentes desenvolvam reflexões mais próximas da realidade vivida. Para tanto, é necessário fraturar o ideal jurídico iluminista de onipotência e de autonomia do indivíduo pelo reconhecimento social no âmbito intersubjetivo (FLICKINGER, 2011). Mais do que um novo padrão a ser seguido, trata se de uma ofensiva para a viabilização e visualização de novos conceitos, práticas e modos de viver, ser, estar e pensar abrindo-se para desaprendizagens e para a reflexão (WALSH, 2008).

Nesse sentido, é fundamental que a Universidade se amplie para a diversidade de vivências. Em regra, estudantes de direito têm um perfil, no Brasil, de jovens, brancos, de classe média, sem filhos/as, e que não conseguem entender as dores reportadas pelas mulheres. Esse perfil tem se alterado com as ações afirmativas. Na Universidade Federal do Pará, há políticas de ações afirmativas que garantem maior acesso para indígenas, quilombolas, refugiados, pessoas com deficiências, pretas e oriundas de escola pública, mas ainda são muitos os desafios na elaboração e gestão de políticas que superem as dificuldades apresentadas na trajetória acadêmica destes estudantes e garantam a conclusão do curso ou a igualdade de oportunidades durante a formação (PORTELA et al, 2015).

Desta forma, o perfil da maioria dos/as estudante concluintes ainda é distante das mulheres atendidas, em sua maioria pobres, periféricas, negras, com filhos/as. Esse abismo também se apresenta para mim, como mulher branca e que, durante muito tempo, não incorporou a centralidade do debate racial em seus estudos e na sua atuação profissional.

Em verdade, falar sobre atendimento jurídico diz muito sobre a branquitude ${ }^{10}$. Isso demonstra a necessidade de estudos sobre ela no ambiente de ensino jurídico em que são poucas as professoras e advogadas negras. Na realidade, não há na Faculdade de Direito da

\footnotetext{
${ }^{10}$ Para Liv Sovik (2009), branquitude é atributo das pessoas brancas, que ocupam um lugar social no alto da pirâmide. É uma prática social e um exercício de uma função que reforça e reproduz instituições.
} 
UFPA uma única professora negra. Estas, no país, são menos de $3 \%$ dos/as docentes ${ }^{11}$. Isso se reflete no ensino e no atendimento desenvolvido. Trabalhos sobre branquitude nesses espaços podem contribuir para desnudar estas dinâmicas.

São muitos os trabalhos que evidenciam os efeitos do racismo na população negra, mas pouco se apresentam os efeitos no segmento dominador. Para Carlos Wedderburn (2005), o racismo cria para essas pessoas uma complexa rede de atitudes de cumplicidade amoral, de insensibilidade humana, que por sua vez propiciam um alto grau de permissividade diante de certas condutas como o desrespeito à lei. Isso traz impactos que inviabilizam muitas vezes um atendimento com sensibilidade às demandas relatadas. São métodos brancos de ensino e de atendimento jurídico para pessoas brancas atenderem pessoas negras.

Observa-se assim que os limites curriculares e de formação, a falta de diversidade discente e docente, a falta de estrutura adequada, além das demais questões evidenciam o quão tortuoso é o caminho para que esses espaços universitários efetivamente promovam direitos e tensionem as hegemonias do ensino jurídico.

Isso mostra a necessidade de avançarmos no sentido de uma agenda mais ético política. Uma agenda que confronte os limites do ensino jurídico e do Direito e aponte para bases comprometidas com a vida das mulheres. É necessário tencionar as lógicas de poder e as violências universitárias e as lógicas de poder e de violência que atravessam a vida dessas mulheres.

\section{Ensino jurídico e violência: por bases comprometidas com a vida das mulheres}

No atendimento às mulheres em situação de violência há mais coisas que separam as pessoas atendendo e as mulheres atendidas do que as mesas. Há, em verdade, universos distintos. Em uma perspectiva fanoniana, há um abismo entre a zona do ser (de quem atende) e a zona do não-ser (de quem é atendido). Fanon (2008) fala da existência de uma zona do não-ser, uma região extraordinariamente estéril e árida, habitada pela população negra. Tratase de uma zona heterogênea, em que o desprivilégio é entrecortado por diversos outros eixos de poder: classe, gênero, religiosidade, idioma, sexualidade, nacionalidade, dentre outros

\footnotetext{
${ }^{11}$ GÊNERO E NÚMERO. Menos de 3\% entre docentes da pós-graduação, doutoras negras desafiam racismo na academia. Disponível em: http://www.generonumero.media/menos-de-3-entre-docentes-doutorasnegras-desafiam-racismo-na-academia/. Acesso em: 20 out. 2020.
}

Revista de Pesquisa e Educação Jurídica | e-ISSN: 2525-9636 | Encontro Virtual | v. 7 | n. 2 | p. $01-20$ | Jul/Dez. 2021. 
(GROSFOGUEL, 2012). De outro, a zona do ser, espaço de reconhecimento de direitos e privilégios.

No atendimento impõe-se geralmente um processo de tradução da vivência das pessoas para a linguagem jurídica. Isso impede, muitas vezes, que haja efetivamente o enfrentamento às violências impostas, pois o universo jurídico pulveriza as demandas que terminam sendo observadas de forma individualizada, distante e judicializada. Isso torna a assistência jurídica oferecida precária. A violência não pode ser vista de forma pontual na vida dessas pessoas. É fundamental ampliar a nossa noção de violência e questionar de que violências estamos falando.

Para Oyèwúmi (2000), o solipsismo branco é muito decisivo e prejudica a percepção da hierarquização de humanidade baseada na raça como algo que estrutura as violências perpetradas. Isso faz com as violências contra as mulheres negras não sejam devidamente percebidas em sua dinâmica racial e estrutural. Segundo Creenshaw (1991), a localização das mulheres negras na intersecção entre raça e gênero, por exemplo, torna a experiência de violência doméstica qualitativamente diferente da vivida pelas mulheres brancas. Em alguns casos, a agressão física é apenas a manifestação mais imediata de opressão que as políticas públicas devem lidar havendo outras, às vezes mais profundas, como a sobrecarga familiar, a falta de emprego ou moradia adequada. Estas questões dificilmente são enfrentadas, pois o foco é a ação judicial.

Segundo Flauzina (2015), a violência contra as mulheres negras tem suas especificidades e está inscrita com a forma brutal com que essas mulheres têm sido tratadas em nossa sociedade. Infelizmente estudos sobre a Lei Maria da Penha e os debates sobre as formas de intervenção não tem abordado isso, o que contribui para o silenciamento dessas dimensões de abusos. Meus estudos em particular pouco tiveram esse foco de preocupação. Isso impede que mulheres não-brancas acessem meios para vincular suas experiências, o que traz a sensação de isolamento e emudecimento.

Além das noções de violência, também são diferentes as percepções sobre o processo de intervenção. Estes/as discentes se sentem mais preparados/as, com sua formação dogmática e tecnicista, para dar respostas prontas do que para ouvir as demandas, entender e construir, 
em conjunto, soluções com as mulheres interessadas. Até porque eles/as imaginam possuir o saber competente e autorizado. ${ }^{12}$

É fundamental construir um processo de escuta ativa para fortalecer as mulheres e a assistência jurídica prestada. Felipe Fernandes (2014) analisa a "escuta ativa" como formas de engendrar práticas de reconhecimento da realidade social e pela elaboração de políticas de comprometimento dos sujeitos com o objetivo de transformar a realidade. Isso, todavia, não é possível em um ambiente marcado por hierarquias e relações de poder.

É preciso, assim, ir além das hierarquias que permeiam o ambiente universitário jurídico para que possamos, de fato, aprender com quem, a despeito do Estado, se mantém vivo e para que possamos observar outras formas de resistência, além dos conhecimentos produzidos nesses espaços. Lidar com essas pessoas sem hierarquia de humanidade significa pensar o direito a partir de bases comprometidas com a vida.

Isso envolve refazer o pacto de igual humanidade, pois significa reconhecer essas pessoas a partir do humano. Ouvir suas experiências e realidades e reconhecer as estratégias de justiça do vivido, muitas vezes desenvolvidas diante dos limites do direito. Reconhecer a subjetividade dessas mulheres, marcada pela afirmação de direitos.

Segundo Thula Pires (2018), o que nos mantêm divididos entre as zonas do ser e do não ser é a conversa inacessível a alguns corpos, narrativas e saberes. Um atendimento em outros termos, nos termos de quem é atendido, não tira essas mulheres da zona do não ser, mas mitiga o sofrimento e o processo de desumanização.

Essas questões permitem refletir sobre a própria noção de assistência jurídica. Para Jaciara Alves (2019), assistência jurídica é o instituto que permite que as pessoas pobres financeiramente conquistem o seu direito, livre e sem burocracia, de peticionar judicialmente. Moraes (1999) traz uma visão mais ampla compreendendo toda a extensão de atos jurídicos, tais como representação em juízo, atos jurídicos extrajudiciais e concessão de atividades de consultoria, encerramento o aconselhamento, a informação e a orientação em assuntos jurídicos.

Ambos os conceitos, contudo, centram-se na dimensão do jurídico e pouco na do atendimento. Este não é foco destas políticas. Até porque a dinâmica envolve mais o falar do

\footnotetext{
${ }^{12} \mathrm{O}$ discurso competente é aquele considerado aceito, verdadeiro e autorizado, proferido de um ponto determinado da hierarquia social e organizacional (CHAUÍ, 2007).
} 
que o ouvir ou o interagir. Isso me levou, ao longo do tempo, a questionar também os limites do próprio atendimento, seu significado e alcance.

Atender alguém na qualidade de vítima é estabelecer uma distância intransponível entre a assistida e aquela que assiste. Trata-se de uma troca muito desigual (DEBERT e PERRONE, 2018). Entender e intervir sobre o fenômeno das violências cometidas contra as mulheres, contudo, significa ouvir essas mulheres. Estas, na verdade, têm sido silenciadas durante um longo período histórico, repletas de interlocutores, encerradas no "lugar de vítimas" ou de "sedentas de vingança". Suas imagens são mantidas simplesmente para ampliar o problema, não para humanizar suas experiências (CREENSHAW, 1991).

Para Grada Kilomba (2016), o ato de falar é como uma negociação entre quem fala e quem ouve, ou seja, entre os sujeitos falantes e seus/suas ouvintes. Ouvir é, neste sentido, o ato de autorização para quem fala. Eu só posso falar, se a minha voz for ouvida. Ser ouvida significa pertencer, o que não é possível nessas configurações de conhecimento e de poder.

Esse silenciamento produz efeitos na subjetividade das pessoas. Precisamos que seja narrada a violência para que não tenhamos a violência. A violência, nas suas múltiplas formas, é sempre a negação dos sujeitos e a emergência desta mulher pode ajudar no combate à própria violência construindo uma memória histórica e novas perspectivas de reconhecimento (DEBERT e PERRONE, 2018).

É fundamental narrar entender o que se vive, olhar, e ver as possíveis saídas. A narrativa é espaço de memória e da reparação. Ao narrarem acontecimentos que marcaram suas trajetórias, as mulheres convidam a sentir a dor de seus corpos (DAS, 2008), todavia, o direito não quer saber do sofrimento, não confere lugar para essas narrativas.

Muitas vezes, entretanto, não é no Direito que serão encontradas as saídas. Por outro lado, oferecer o Direito de forma descuidada como saída é ignorar que este é um espaço de dor. Em verdade, longe de se oferecer cura e ou respostas salvíficas deve-se tentar diminuir as dores oferecidas pelo sistema e construir respostas em conjunto com quem vivencia essas experiências e pode escolher a melhor forma de lidar sem agência.

Há, contudo, muitas vezes uma visão oportunista que utiliza das falas das mulheres para justificar as agruras do sistema. Se vai de um extremo ao outro. Muitas pessoas simplificam a análise e dizem, por exemplo que não devem ser tomadas medidas penais porque "as mulheres não querem a prisão" (DEBERT e PERRONE, 2018). Isso é deixar de reconhecer a complexidade da fala e da escuta diante do leque de escolhas abertas em 
diferentes momentos. Essa fala é feita em um contexto e é, muitas vezes, verbalizada diante de uma situação em que se vê a falta de saídas perante o sistema criminal. Isso não deve, todavia, terminar por responsabilizar as mulheres pelos problemas do Judiciário na solução desses casos.

\section{Considerações finais}

Ao longo de cerca de quinze anos no atendimento a mulheres em situação de violência, pude observar inúmeros desafios e mudanças nos modelos de assistência, principalmente a partir de uma perspectiva de formação docente. Durante este período, foram diversas as iniciativas desenvolvidas na tentativa de permitir novos modelos de formação que possibilitassem maior preparo discente para o atendimento às mulheres em situação de violência, além de oferecer, na universidade, um espaço para esse tipo de serviço.

O desenvolvimento de ações, como a Clínica de Atenção à Violência, revelou avanços no sentido de oferecer mais oportunidades para estudantes lidarem com a defesa dos direitos das mulheres. Todavia, ainda há desafios de difícil superação que envolvem os limites do próprio ensino jurídico, do Direito e do atendimento e que precisam ser evidenciados e enfrentados.

Ainda há muito o que se superar ao se confrontar com uma formação tecnicista e manualesca, com uma estrutura curricular com perfil dogmático e pouco voltada para o atendimento humanizado. Ademais o perfil do curso não alcança as experiências destas mulheres, mas é permeado pelas lógicas brancas de ensino e atendimento promovendo uma conversa em termos que não são aqueles vividos por elas.

Desnudar as nuances do atendimento prestado no espaço universitário é fundamental para possibilitar a melhoria deste serviço que tem se constituído enquanto uma das portas de entrada das violências contra as mulheres no sistema e não pode ser negligenciado ou precarizado, mas deve ter como norte a luta pela melhoria de vida dessas mulheres em termos diferentes do que, em regra, se constitui.

Isso exige esgarçar a noção de violência, de atendimento, de ensino e de Direito, por exemplo. Envolve um processo de maior desnaturalização das categorias e das vivências ali permeadas como forma de desnudar as relações de poder que nos cercam e construir uma agenda ético política de mudanças concretas em diferentes terrenos, inclusive a academia.

\section{Revista de Pesquisa e Educação Jurídica | e-ISSN: 2525-9636 | Encontro Virtual | v. 7 | n. 2 |}


O percurso dessa autoetnografia investiga a própria configuração da docência e da advocacia. Nessa autocrítica/autoreflexiva, corporificada de afetos, inquietações e desconfortos, abre-se a possibilidade de se reatualizar o repertório de atuação para novas perspectivas e olhares, com mais cuidado as questões embaçadas pelo caminho. Toda trajetória deve ser constantemente revista sob pena de reproduzirmos comportamentos e práticas estanques e incongruentes com a sociedade complexa que vivemos.

\section{Referências}

ALVES, Jaciara Barreto de Souza. Distinção entre justiça gratuita e assistência jurídica gratuita. Jurisway. Disponível em: https://www.jurisway.org.br/v2/dhall.asp?id_dh=20738. 2019. Acesso em: 27 out. 2020.

BELLO, Enzo; FERREIRA, Lucas Pontes. Clínicas de direitos humanos no Brasil: um estudo sobre seu processo de implementação e funcionamento na prática e no ensino jurídico. Revista de Estudos Constitucionais, Hermenêutica e Teoria do Direito (RECHTD) 10(2):170-182, maio-agosto 2018.

BEZERRA, Selma Silva. Um estudo autoetnográfico em aulas de língua inglesa no ensino médio: reflexões sobre de (colonialidades), prática docente e letramento crítico. Tese de Doutorado em Letras e Linguística. UFAL: Maceió, 2009.

BORGES, Thais Regina Santos. Por um sentir crítico: um olhar feminista interseccional sobre a socioconstrução de identidades sociais de gênero, raça/etnia e classe de professoras de línguas. Dissertação de Mestrado em Direito. Orientadora: Adriana Nogueira Accioly Nóbrega. Puc-Rio: 2017.

BOSSLE, Fabiano; ROCHA, Leandro Oliveira. A autoetnografia como possibilidade de compreensão da própria cultura docente: entre a atuação no campo de trabalho e a continuidade de formação. Anais do XVII Congresso Brasileiro de Ciências do Esporte. Porto Alegre, 2011.

CHAUÍ, Marilena de Souza. Cultura e Democracia: o discurso competente e outras falas. 12a ed. São Paulo: Cortez, 2007.

CRENSHAW, Kimberle Williams. Mapping the Margins: Intersectionality, Identity Politics, and Violence against Women of Color. Stanford Law Review. vol. 43. N. 6. 1991. 1241-99.

DAS, Veena. "El acto de presenciar. Violencia, conocimiento envenenado y subjetividad" In: ORTEGA, Francisco (Org.). Veena Das: sujetos del dolor, agentes de dignidad. Bogotá: Universidad Nacional de Colombia, 2008: p. 343- 374. 
DEBERT, G. G.; PERRONE, T. S.. Questões de poder e as expectativas das vítimas: dilemas da judicialização da violência de gênero. Revista Brasileira de Ciências Criminais. v. 150, n. 26. p. 423-47. dez. 2018.

FANON, Frantz. Pele negra, máscaras brancas. Salvador: EdUfba, 2008.

FERNANDES, Felipe Bruno Martins. Os desafios da "Escuta Ativa": manifesto por uma gestão queer em políticas feministas e LGBT. Revista Periódicus. maio-outubro de 2014. Disponível em: www.portalseer.ufba.br/index.php/revistaperiodicus/index. Acesso em: 9 abr. 2020.

FLAUZINA, Ana Luiza Pinheiro. Lei Maria da Penha: entre os anseios da resistência e as posturas da militância. FLAUZINA, Ana; FREITAS, Felipe; VIEIRA, Hector; PIRES, Thula. Discursos negros: Legislação penal, política criminal e racismo. Brasília: Brado Negro, 2015, p.121-151.

FLICKINGER, Hans-Georg. Herança e futuro do conceito de formação (Bildung). Educ. Soc., Campinas, v. 32, n. 114, p. 151-167, Mar. 2011. Disponível em: <http://www.scielo.br/scielo.php?script=sci_arttext\&pid=S010173302011000100010\&lng=en\&nrm=iso>. Acesso em: 09 abr. 2020.

FUNDO BRASIL DE DIREITOS HUMANOS. Litigância estratégica em Direitos Humanos. Experiências e reflexões. São Paulo: Fundo Brasil de Direitos Humanos. 2016. 124 p. Disponível em: http://www.fundodireitoshumanos.org.br/wpcontent/uploads/2016/12/ litigancia-estrategia-1.pdf. Acesso em: 09 jun. 2020.

GROSFOGUEL, Ramón. La descolonización del conocimiento: diálogo crítico entre la visión descolonial de Frantz Fanon y la sociología descolonial de Boaventura de Sousa Santos. 2012 Disponível em: http://www.iepala.es/IMG/pdf/AnalisisRamon_Grosfoguel_sobre_Boaventura_y_Fanon.pdf. Acesso em: 1 abr. 2020.

HARAWAY, Donna. Saberes localizados: a questão da ciência para o feminismo e o privilégio da perspectiva parcial. Cadernos Pagu (5), Campinas-SP, Núcleo de Estudos de Gênero - Pagu/Unicamp, 1995, pp.7-41.

HOOKS, bell. . Teaching to transgress. New York: Routledge, 1994.

HURWITZ, Deena R. Engaging Law students through human rights clinics: a perspective from the United States. Australian Journal of Human Rights - AJHR. Sidney, 11.2 (2), p. 37-51, 2006.

KILOMBA, Grada. Descolonizando o conhecimento: uma palestra-performance de Grada Kilomba. 2016. Tradução: Jessica Oliveira. Disponível em: http://www.goethe.de/mmo/priv/15259710-STANDARD.pdf. Acesso em: 6 ou. 2020.

LAPA, Fernanda Brandão. Clínicas de Direitos Humanos: uma proposta pedagógica para a educação jurídica no Brasil. Rio de Janeiro: Lumen Juris, 2014. 
MENDES, Renato Nureyev; REIS, Jair Teixeira dos. Entre a formação humanista e a tecnicista: perspectivas do ensino jurídico e do bacharelismo no Brasil - do auge ao declínio. Revista da Faculdade de Direito-RFD-UERJ. Rio de Janeiro, n. 30, dez. 2016.

MORAES, Guilherme Peña de. Instituições da Defensoria Pública. São Paulo: Malheiros, 1999.

OYÈWÚMI, Oyèronké. Family bonds/Conceptual Binds: African notes on Feminist Epistemologies. Signs, Vol. 25, No. 4, Feminisms at a Millennium (Summer, 2000), pp. 1093-1098.

PIEDADE, Vilma. Dororidade. São Paulo: Editora Nós, 2017.

PIMENTEL, Geyza Alves. Universidade e políticas de extensão no Brasil do governo Lula: período de 2003 a 2010. Tese de doutorado do Programa de Pós-Graduação em Ciência Política. Universidade Federal do Rio Grande do Sul. 2015.

PIRES, Thula Rafaela de Oliveira. Estruturas Intocadas: Racismo e Ditadura no Rio de Janeiro. Rev. Direito Práx. [online]. 2018, vol.9, n.2, pp.1054-1079. ISSN 21798966. http://dx.doi.org/10.1590/2179-8966/2018/33900.

PORTELA, Rosele; LIMA, Aline; ARAÚJO, Izabel; SILVA, Walkiria. A trajetória das políticas de ações afirmativas para indígenas e quilombolas na Universidade Federal do Pará. Anais da VII Jornada Internacional de Políticas Públicas. 2015.

SANTOS, Boaventura. A Universidade do Século XXI: para uma reforma democrática e emancipatória da Universidade. São Paulo: Cortez, 2005.

SOUZA, Firmiane Venâncio do Carmo. As Marias do Carmo: memórias de três gerações de mulheres no sertão baiano. Revista Feminismos. v. 7, n. 2. 2019.

SOUZA, Luanna Tomaz de; SILVA, Ana Beatriz Freitas; YOSANO, Yasmim Nagat. Fios e furos nos entrelaçamentos teóricos e metodológicos nas pesquisas criminológicas sobre mulheres. In: Revista Brasileira de Ciências Criminais. Vol. 153. Ano 27. São Paulo: RT, 2019. p. 243-264.

SOUZA, Luanna Tomaz de. "Será que isso vai pra frente, doutora?" Caminhos para a implementação da Lei "Maria da Penha" em Belém. 236 f. Dissertação (mestrado) Universidade Federal do Pará. Orientação da Professora Doutora Monica Conrado. Belém: UFPA, 2009.

SOUZA, Luanna Tomaz de.; LOPES, A. B. A.; SILVA, A. F. O NEAH e a atenção ao autor de violência doméstica e familiar contra a mulher em Belém. Revista Brasileira de Políticas Públicas, v. 8, p. 378-395, 2018.

SOUZA, Luanna Tomaz de.; PINHEIRO, I.; VELOSO, M. M. X. A experiência do Pro Paz mulher: reflexões acerca dos limites e potencialidades dos centros integrados. In: PASINATO, Wânia; MACHADO, Bruno; ÁVILA, Thiago. (Org.). Políticas públicas de prevenção à violência contra a mulher. São Paulo: Marcial Pons, 2019, v. 1, p. 227-252.

Revista de Pesquisa e Educação Jurídica | e-ISSN: 2525-9636 | Encontro Virtual | v. 7 | n. 2 | p. $01-20$ | Jul/Dez. 2021. 
SOUZA, Luanna Tomaz; TEIXEIRA, Eliana Maria de Souza Franco; MESQUITA, Valena Jacob. As novas diretrizes curriculares de direito e as novas dinâmicas da prática jurídica na Universidade Federal do Pará (UFPA). Revista ESMAT. Ano 12 - n. 19. p. 113 - 128 jan. à jun. 2020.

SOUZA, Luanna Tomaz. Da expectativa à realidade: a aplicação de sanções na Lei Maria da Penha. Tese de Doutorado. Orientação da Professora Doutora Cecília Macdowell. Coimbra-Portugal: Universidade de Coimbra: 2016.

SOVIK, Liv. Aqui ninguém é branco. Rio de Janeiro: Aeroplano, 2009

WALSH, Catherine. Interculturalidad, Estado, Sociedad: Luchas decoloniales de nuestra época. Quito, Universidad Andina Simón Bolívar; Abya Yala. 2008.

WEDDERBURN, Carlos Moore. Novas bases para o Ensino da História da África no Brasil abertos pela Lei Federal 10.639/03. Brasília: MEC-SECAD, 2005. 